\title{
The X-Factor of Cultivating Successful Entrepreneurial Technology-Enabled Start-Ups
}

\author{
Elsje Scott, Terrina Govender, and Nata van der Merwe \\ University of Cape Town, Cape Town, South Africa \\ elsje.scott@uct.ac.za, terrina@datalifeafrica.com, \\ nata@smartsearch.co.za
}

\begin{abstract}
In the fast changing global economic landscape, the cultivation of sustainable entrepreneurial ventures is seen as a vital mechanism that will enable businesses to introduce new innovative products to the market faster and more effectively than their competitors.

This research paper investigated phenomena that may play a significant role when entrepreneurs implement creative ideas resulting in successful technology enabled start-ups within the South African market place. Constant and significant changes in technology provide several challenges for entrepreneurship. Various themes such as innovation, work experience, idea generation, education and partnership formation have been explored to assess their impact on entrepreneurship.
\end{abstract}

Reflection and a design thinking approach underpinned a rigorous analysis process to distill themes from the data gathered through semi structured interviews. From the findings it was evident that the primary success influencers include the formation of partnership, iterative cycles, and certain types of education. The secondary influencers included the origination of an idea, the use of innovation. and organizational culture as well as work experience.

This research illustrates how Informing Science as a transdisicpline can provide a philosophical underpinning to communicate and synthesise ideas from constituent disciplines in an attempt to create a more cohesive whole. This diverse environment, comprising people, technology, and business, requires blending different elements from across diverse fields to yield better science. With this backdrop, this preliminary study provides an important foundation for further research in the context of a developing country where entrepreneurial ventures may have a socioeconomical impact. The themes that emerged through this study could provide avenues for further research.

Keywords: entrepreneurial start-ups, partnerships, education, idea generation, innovation, design thinking, common features for the foundation of a

(CC BY-NC 4.0) This article is licensed to you under a Creative Commons AttributionNonCommercial 4.0 International License. When you copy and redistribute this paper in full or in part, you need to provide proper attribution to it to ensure that others can later locate this work (and to ensure that others do not accuse you of plagiarism). You may (and we encourage you to) adapt, remix, transform, and build upon the material for any non-commercial purposes. This license does not permit you to use this material for commercial purposes. successful company

\section{Introduction}

In recent years, there has been a world-wide drive for innovation and the nurturing and valuing of creative ideas that will result in successful entrepreneurial ventures. Managing creativity in order to advance innovation is a vital challenge, and consequently managing ideas will become more and more important to ensure organizational growth 
(Cohendet \& Simon, 2015). This is of particular importance in developing countries like South Africa where research has shown a recent drop in entrepreneurial activities (GIBS, 2009). Cohendet and Simon (2015) also contend that, while ideas are the basic cornerstones (foundations) of creativity and innovation, new ideas are not enough to generate and drive innovation. Producing an idea is only the start and must be followed by a process converting and realizing the potential of the idea. Developing and realizing ideas is what constitutes the innovation process.

Many universities include the notion of innovation in their mission and value statements to generate new ideas that will create alternative ways of thinking when solving real world problems. Nurturing the development of new products, processes, and services in this way can benefit society and should be encouraged. Matthews (2007) confirms that creativity and entrepreneurship have been identified as important stimuli of economic growth. She also suggests that creative thinking practices are beneficial for entrepreneurship or for starting a new venture. Cooke and Zaby (2015) explored the skills that technology start-ups view as important and that graduates seem to be in need of. They found that creative drive as well as original idea contribution were ranked in the top 10. Peppard and Ward (2004) contend that the competitive ability of organizations relies heavily on the effective use of Information Technology(IT) and Information Systems(IS).

The Gordon Institute of Business Science (GIBS) (2009) outlined that the Total Entrepreneurial Activity (TEA) in South Africa was 7.8\% in 2009. This figure is in line with what the Global Entrepreneur Monitor (GEM) reports (2010-2014) reflected, namely 8.9\% in 2010, compared to $9.1 \%$ in 2011 and $7.3 \%$ in 2012. In 2013, a 13-year high of 10.6\% was reported, which dropped sharply in 2014 to $6.79 \%$ (Singer, Amoros, \& Arreola, 2014). This sharp drop indicates that somehow something is going wrong with regard to entrepreneurs and start-ups in South Africa, and therefore it is both relevant and important to investigate the differentiating factor, or the Xfactor, of successful technology-enabled start-ups.

This paper reports on a study that was executed at the University of Cape Town as a search to identify phenomena that play a significant role when entrepreneurs implement creative ideas that, specifically in this case, resulted in successful technology-enabled start-ups. In order to answer the questions of how ideas originate and how a certain mind-set can encourage the generation and successful implementation of entrepreneurial ideas, some core principles such as entrepreneurial partnerships, the impact of education and work experience on entrepreneurship, amiable entrepreneurial environments, and innovation were examined. In addition to this, since technology has become ubiquitous in the business environment, it was also necessary to explore how the complexities and chaos often brought about by human and technology interaction impact innovation and entrepreneurship.

There are parallels between how designers would approach design problems and the way in which business problems are solved. In the Sciences of the Artificial, Herbert Simon (1996) calls for the establishment of a rigorous body of knowledge about the design process as a means of approaching managerial or business problems. Roger Martin (2009) believes that "design thinking" offers a third alternative to analysis and intuition when solving business problems. Problems, and specifically business problems for that matter, are not always a given; in most cases, the real problem first needs to be identified and then named or framed (Schön, 1983). Entrepreneurs as innovation practitioners should use design thinking to observe the world, imagine alternatives, and bring them into being. The communication of knowledge accumulated during the design phase becomes an integral part of the implementation process. This is of particular interests to informing science as it provides mechanisms of sharing this knowledge and information with business and the world in "a form, format, and schedule that maximizes its effectiveness" (Cohen, 1999). For example, Martin $(2009,2010)$ uses the analogy of a "knowledge funnel" (see Figure 1) to explain how innovations and problem identification start as intriguing mysteries. The knowledge funnel comprises three stages. The discovery process in the mystery, or first phase, 
starts as a search for alternative solutions that will lead to the development of workable "heuristics" as a second step. As these solutions are refined and step by step procedures can be defined, predictable "algorithms" can be derived, denoting the third and last step in the knowledge funnel. In their discovery and exploration process of a situation of concern that may present itself as a problem, people need analysis and creative thinking at different points in that funnel, leading them to innovate more consistently and successfully. In depicting this flow of data and knowledge between research and practice, Gill (2015a) mentions a similar analogy that perceives the problem space as three different spaces: the state space of facts and knowledge (mystery); the operator space of logic and mathematical patterns (heuristics), and the goal space of utility (algorithms). In this research, the knowledge funnel acted as a theoretical framework that guided the research process and the findings.

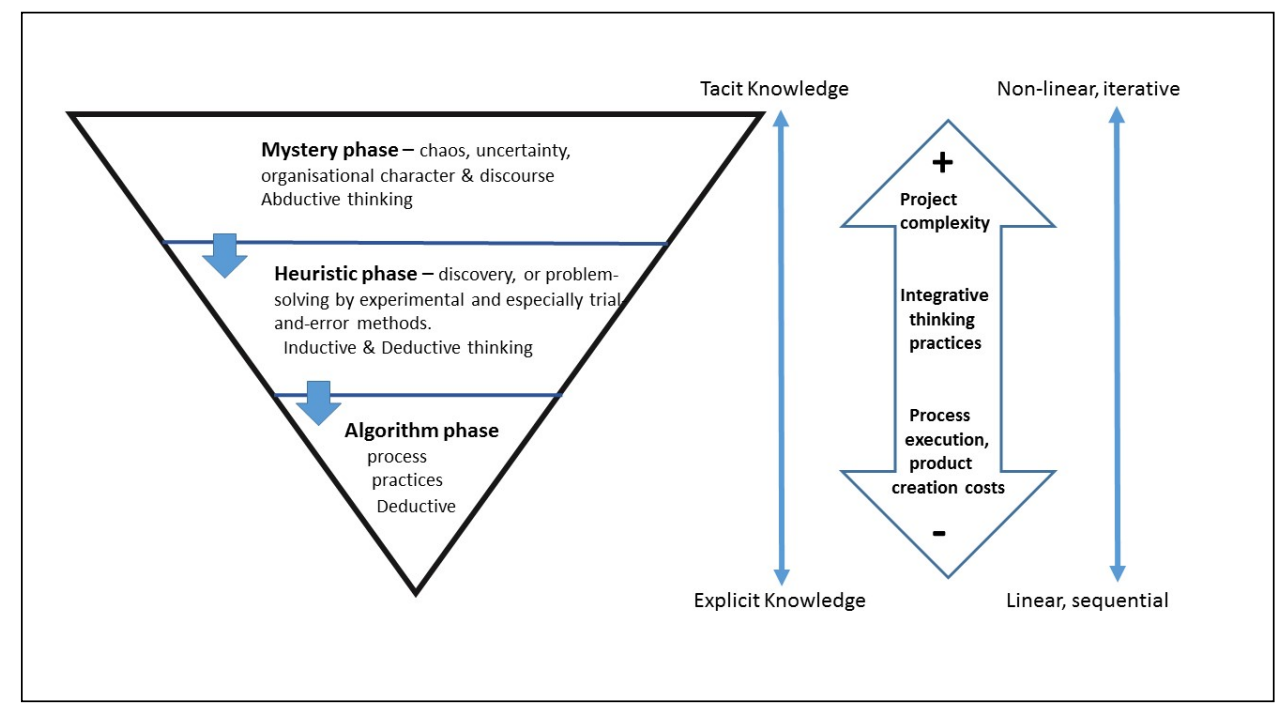

Figure 1: The Knowledge Funnel (adapted from Roger Martin (2009)

In the Informing Science discipline, metaphors and mental models are not only powerful to "transfer ways of thinking and /or" applying "existing knowledge to new and different situations", but also for communicating this to the broader community (Cohen, 2009). According to Leshem and Trafford (2007), a conceptual framework or model is invaluable in the process as it acts as a bridge between different disciplines. Mental or conceptual models also act as vehicles to cope with the uncertainties of different disciples and environments. Successful entrepreneurs develop conceptual models to make sense of uncertainties and then to communicate this information to convince others and gain their support (Hill \& Levenhagen, 1995). An outcome of this study was a conceptual model as a heuristic, comprising (incorporating) the phenomena for cultivating technology enabled business ventures initiated by a framework of ideas. Gill (2011) argues that the development of a conceptual model or scheme can be seen as the search for what is useful in contrast with the development of a theory that can be viewed as the search for what is true. With this study, the intention was towards the useful, to lay a foundation for future research that could develop the heuristic into a more comprehensive framework that will enable more entrepreneurs to develop ideas into business ventures, thereby increasing the TEA.

The next section of this paper will provide an overview of the literature with a specific focus of the main phenomena that might influence entrepreneurial start-ups. This is followed by a brief summary of the research methodology. Next, the major themes that emerged from thematic analysis of the interviews with eight participants are presented, followed by a discussion of the findings and the conclusion. 


\section{Literature Review}

Man's mind, once stretched by a new idea, never regains its original dimensions (Oliver Wendell Holmes).

Before we can gain a better understanding of how innovative ideas can be escalated to become successful business ventures, we have to obtain a deeper understanding of the complex and often chaotic world we live in. From the literature, it is evident that the chaos and complexity is brought about by the interaction of business, people and technology. It becomes essential for professionals to take actions and establish entrepreneurial ventures that will lead to harmony and cohesion when human and technology platforms are connected.

\section{The Chaotic Nature of the World}

In this world we are confronted with both the natural and the artificial. Natural science is the body of knowledge for a class of objects or phenomena, their attributes and properties and how they behave and interact with one another (Simon, 1996). The focus in the natural sciences is to find a pattern or law to simplify complexity, creating order from chaos. Simon (1996) argues that in contrast to natural science is the sciences of the artificial. The sciences of the artificial is the body of knowledge of manmade objects and phenomena and their behavior in relation with one another. Integral to this is the science of design that refers to the designing and the making of artificial things, artefacts, as Simon (1996) calls them. Since design is about how things ought to be, these artefacts could be abstract or concrete objects or phenomena. The dilemma here is that informing science perspectives do not provide specific guidance in designing artifacts for diverse practitioner subgroups like IT experts, executives, and consultants. In addition, the artifacts themselves may range from the very technical, through those including varying social aspects to those comprising social organizational structures, people, and processes (Gill, 2015a). The natural sciences, on the other hand, focus on how things are. As such, design is central to all professional training in various fields such as engineering, architecture, business, and education since "everyone designs who devises courses of action aimed at changing existing situations into preferred ones" (Simon, 1996, p. 111).

As a result of the interaction between the artificial and the natural worlds, the problems that emerge are often ill defined, creating a chaotic world that needs to be viewed multidimensionally. Leavy (2011) argues that these "wicked" or ill-defined problems causes dilemmas as they do not adhere to current or existing models of thinking. A new-mindset or multidimensional thinking strategies may be necessary to find innovative and creative solutions to these problems.

Gill and Murphy's (2011) three-dimensional conceptual scheme of objective complexity, problem space complexity, and unfamiliarity to map design task complexity proposes such a strategy. Within this conceptual scheme, objective complexity means that with a backdrop of rising populations and intense drives for innovation, not only does the number of entities increase at a rapid rate, but "the potential relationships are subjected to combinatorial explosion" (Schmitt, 2015, p. 159). Problem space complexity refers to the vastness of the problem space, the multitude of alternative solutions, and the numerous constraints that may exist. In addition to this, specialization and domain specific knowledge aggravate the situation by creating a fragmented reality. Leavy (2011) refers to integrative thinking as a strategy in these situations to harness "the tensions creatively" when evolving better solutions. Like in the mystery phase of the knowledge funnel, unfamiliarity "represents the absence of task specific knowledge". In these landscapes of difficult problems, little guidance exists on how to approach these ill- structured situations of concern, and tools to make sense of them of are often inadequate and not fit for purpose at all. 


\section{Connecting the Human/Technology Platforms}

The Information Systems (IS) discipline, a contributing discipline within the discipline of Informing Science (Gill, 2011), involves the study of information and information systems in a social setting, as well as the effects that this interaction has on the total system comprising people, technology, data, processes, organizations, and society (Hirschheim \& Klein, 2012; Walsham, 2012). The rich phenomena that emerge as a result of this interaction have great significance for creating a changed mind-set and an awareness that the focus is both on people and technology. The IS field, therefore, draws on both behavioral science and design science (Hevner, March, \& Park, 2004). Behavioral sciences are embedded in the natural sciences and looks to cultivate principles that explain human phenomenon and behavior with regard to the use, analysis, design, and implementation of IS. Design science, on the other hand, "seeks to create innovations that define the ideas, practices, technical capabilities, and products through which the analysis, design, implementation, management, and use of information systems can be effectively and efficiently accomplished" (Hevner et al., 2004).

Since an artefact is used to describe a manmade or artificial thing, Simon (1996) argues that it can also be an "interface" to describe the interaction of the inner environment that deals with the essences of the artefact and the outer environment, the surroundings in which it operates. The contingency of an artefact to fulfil its intended purpose is based on the compatibility and harmony of the inner and outer environment (Simon, 1996).

Making sense of the interactions of the different environments and paradigms described above, and obtaining a deep understanding of the harmony and cohesion that needs to be created when they interact, becomes essential for innovation in an IS context and in establishing an entrepreneurial venture. Mezirow (1990) argues that making sense of our experiences is equivalent to its interpretation. This can be affected through reflection. When we use "interpretation to guide decision-making or action, then making 'meaning' becomes 'learning"'. When reflection enables us to "correct distortions in our beliefs and errors in problem-solving" our learning becomes "the process of making a new or revised interpretation of the meaning of an experience", which may lead to innovation (Mezirow, 1990, p. 1). It is this desire of creating a resolution based on interpretation and interaction that pushes us forward in a subjective world where theory and practice are inseparable and the sense making process is forever intentional and context depended (Gill, 2015b).

\section{The Relevance of Reflection for Professionals}

Schön (1983, p. 3) argues that professionals are "essential to the very functioning of our society", the value they bring to society is encompassed in their ability to adequately identify and define a problem and then subsequently formulate effective solutions. As IS professionals continuously go through this process of problem solving, reflection becomes an essential part of this process, as we have seen above. It is, however, not only the "systematically stepping back and reflecting on what is happening and why" (Gabrielsson \& Politis, 2012). If we allow reflection to become more than just a cognitive meaning making activity and include "non-cognitive dimensions of human consciousness" to get in touch with our feelings, emotions, anxieties, discomforts, and intuitions, a much richer process unfolds (Jordi, 2011, p. 184).

Professionals were previously taught the correct answers to questions that may arise in their careers. In the $21^{\text {st }}$ century, there has been a shift from knowing the answer to grappling with complexities and being challenged to adapt as a solution to an ill-defined problem unfolds. The effect of this is twofold. Mezirow $(1997$, p. 5) holds that transformative or adaptive learning harnesses autonomous thinking in adults and "is the process of effecting change in a frame of reference". These challenges often also require professionals to 'think on their feet', "adjusting [their] 
responses spontaneously in pursuit of a more collaborative exchange, actively checking on ways, there and then, to turn the conversation in a different direction, and engaging in [their] share of responsive interaction", a concept that Schön (1983) refers to as reflection-in-action (Yanow \& Tsoukas, 2009, p. 1340). Yanow and Tsoukas (2009, p. 1375) extend Schön's concept reflectionin-action to "articulate more clearly the way improvisational responses emerge in the midst of action" by including the roles that surprise and evaluation plays in both the mental and emotional challenges experienced in the moment.

The need for transformative learning thus goes hand in hand with the concept of reflection in action. Both these concepts constitute critical factors in the ability of professionals to adapt to changing conditions, practice critical reasoning, and participate effectively in collaborative environments.

The constant pursuit of innovation and process improvement for the organization is heightened by using reflection-in-action to identify opportunities as well as to cope with wicked problems (Yanow \& Tsoukas, 2009). When the foundations have been laid, concepts such as 'how ideas form' and innovation can be better understood and modelled.

\section{The Origin and "Stickiness" of Good Ideas and Creativity}

Idea generation has a lot to do with creativity. Already in 1950 Guilford challenged the restricted view of creativity for not including factors like the sensitivity to problems, the capacity to initiate many different ideas, and the ability to evaluate these ideas. Idea finding also constitutes one of the six stages of the Creative Problem Solving (CPS) program, also called the Parnes-Osborn model developed by Parnes and his colleagues (cited in Matthews, 2007). Matthews (2007) reports that many researchers agree that creativity is more than just the initiation of good ideas. It also refers to the selection, evaluation, and implementation of ideas. Although original ideas can gain success, this is often not enough. Johnson (2011) argues that ideas do not exist in isolation, but greater success is possible when ideas are built onto existing ones, even if those were not successful before. Idea aggregation and combination, often from completely diverse sources, can cause transformation and enhance organizational performance (Matthews, 2007).

Gabrielsson and Politis (2012) believe that the generation of new business ideas forms an important part of an entrepreneurial process. The ability of entrepreneurs to produce new ideas is linked to whether the entrepreneur has cultivated a learning mindset that not only favors exploration, but also depends on to what extent the entrepreneur can identify an unmet business need that may be turned into business value and profit. In this exploration conceptual frameworks illuminate various possibilities in diverse, uncertain, and complex environments and sharpen the focus for finding better solutions for these unmet business needs. Gill (2015a, pp. 54-55) argues that conceptual models "have a considerable edge over theory" when communicating ideas and possible solutions to business and the broader community. Conceptual models facilitate the "stickiness" of ideas and solutions that resonates better with a target community.

Managing creativity in order to accelerate and improve innovation is the key management challenge that will be faced by companies in the coming years, and this challenge will be faced in an environment of ever-increasing complexity. (Cohendet \& Simon, 2015, p. 5)

\section{Innovation, Entrepreneurship, and Design Thinking}

As a result of this drive for innovation, this study was concerned with investigating at what stage of the entrepreneurial journey innovation is most important for those who created and executed their ideas resulting in successful businesses ventures. Dodgson, Gann, and Coopmans (2008) describes innovation as a key element of competitive advantage and the livelihood of all organi- 
zations. Audretsch and Belitski (2015) identify knowledge, motivation, and skills as the central components of innovation and believe that the nurturing of knowledge and skills should be the main concern of a new entrepreneurial business. Okpara (2007) describes innovation as the successful exploitation of new ideas. He believes that all innovation starts with creative ideas, and therefore creativity is the point of departure for innovation. Innovation is the process that converts new ideas into value propositions. Carayannis Samara, and Bakouros, (2014) agree and state that an invention or the creation of something new is of no significance unless it can be used to add value to the business or organization. However, Okpara (2007) emphasizes that you cannot innovate without creativity.

This is echoed by Naggar (2015) who states that creativity plays a vital role in the innovation process by producing the ideas that instigate innovation. However, he warns that it is knowledge that makes it possible to execute the ideas and, consequently, to innovate. Knowledge feeds creativity. Matthews (2007) points out the irony of creativity - it is based on previous knowledge and could well be a combination of existing knowledge or maybe it is the ability to move past the constraints of existing knowledge to produce and explore new ideas.

According to Okpara (2007), successful entrepreneurs need an edge that comes from the blending of creative ideas and a superior capability to execute these ideas. Zhao (2005) argues that a combination of entrepreneurship and innovation is crucial for the sustainability of a business. He concludes that entrepreneurship and innovation interact to make a business succeed and grow and that this interaction is not limited to the initial stages of a start-up. Campos, Parellada, Quintero, Alfonso, and Valenzuela (2015) conclude that it is more probable that creative individuals will recognize a business opportunity and initiate a new start-up. They suggest that the specific creative thinking style of entrepreneurial individuals correlates highly with the ability to recognize start-up opportunities. These individuals are looking for originality, which calls for more innovation and creativity and requires more new information.

From the above it is clear that unless people (customers and employees) are included into the equation, an innovation process cannot be successful. Design thinking encourages the innovation process with a high velocity as it integrates a human centric approach. This revolves around observing and paying attention to the preferences and needs of people while creating a holistic solution to meet that need and desire (Brown, 2008). This approach is often used to initiate an alternative frame of reference by using tools such as rapid prototyping, drawings, life simulations, and theoretical lenses to extract tacit knowledge, whilst encouraging innovation (Brown \& Katz, 2011).

Historically the element of design was excluded from the developmental process of a concept or a product. The theory of design thinking discards this notion and applies design thinking in the full cycle of such a development process from the inspiration stage, where a problem or opportunity is experienced, through the ideation stage, where ideas are generated and tested, to the implementation stage, for moving to the market. The value of design thinking is thus universal, both corporate and social, since at its core it is about understanding human interaction within any process "essential solution are often very simple, human centered" (Brown \& Wyatt, 2010, p. 29).

The concepts discussed in the literature review and the knowledge funnel, as a theoretical framework, provided a philosophical paradigm to underpin the research methodology. The analogy of the knowledge funnel aids the sense-making process that constantly oscillates between making explicit what is tacit or unravelling complex non-linear problems - from the mysterious to the well-known and proven space. 


\section{Research Methodology}

"The most beautiful thing we can experience is the mysterious. It is the source of all true art and science." (Albert Einstein)

\section{Research Philosophy}

The research philosophy for this study was interpretive in order to understand the entrepreneurial mind-set and the manner in which entrepreneurs perceive and understand opportunities. An interpretive study presumes that people have their own subjective understanding of the world they live in and how they choose to interact with that world (Walsham, 2006). The approach was therefore to gather the various perspectives from the participants and subsequently identify the phenomena that lead to the success of entrepreneurial start-ups.

Phenomenology is the manner in which people understand the world (Saunders, Lewis, \& Thornhill, 2009). This research approach notes that the way people perceive the world is complex and in order to grasp the complexity, the phenomena can be observed and related to similar concepts in order to create understanding (Merleau-Ponty, 1962). The entrepreneurial understanding that will be collected from the sample will use phenomenology inductively. The nature of the research involves a degree of subjectivism and recognition of certain unique characteristics of entrepreneurs.

In using the knowledge funnel as a theoretical framework, the study looked to find a pattern or heuristic within the thinking and actions of the entrepreneurs in the sample considered. In this case, the focus was only on those who created and executed their ideas resulting in successful businesses ventures. Martin (2010) argues that for the path to value creation "neither analysis nor intuition alone is enough". Design thinking, instead, can be used as a strategy to create a dynamic interplay between rigorous analysis and creativity and innovation. "Design thinking enables leaders to innovate along the path of the knowledge funnel, and the firms that master it can gain longterm business advantage" (Martin, 2010, p. 38).

The participants in this study were all students from the same university and all of them qualified with a commerce or IT focused degree over the period 2002 to 2011. This timeframe was chosen as many start-ups need at least two or more years to get off the ground and established. Except in one case where the participant did not complete her honors degree, all entrepreneurs obtained either an honors degree or a four-year business science degree. Although care was taken to minimize bias, the sample of eight includes only one female and one black entrepreneur. A semi structured interview process was used to gather the data. The interviews were then manually transcribed and then coded using a qualitative analysis software product called Nvivo. The coding process with Nvivo extended by the literature, allowed the researcher to explore themes and investigate recurrent themes. The thematic analysis techniques will be applied to illustrate the themes and create a deeper understanding of the phenomena that are significant when starting a technology-enabled entrepreneurial venture (Attride-Stirling, 2001).

\section{Research Design and Data Collection}

Martin (2010) states that a mystery can be refined, whereby irrelevant characteristics are removed and a greater understanding of the problem can be attained. The most effective manner in which to answer the primary research question would be to observe the phenomenon in action and attempt to extract patterns of behavior and thinking from those observations. Interviews were conducted by the initial/primary researcher between May and July of 2013, with two more interviews added before this paper was finalized. Semi structured interviews were used to facilitate the data gathering. 
The contents of the interviews encompassed innovation practices, work methodologies, educational and entrepreneurial history of participants, and suggestions for further analysis.

The interview guide was created with the intention of observing specific traits and knowledge that the selected entrepreneurs possessed. In order to acquire that knowledge, the interview questions were designed according to the following set of parameters:

- History of idea generation and methodologies, specific to the entrepreneurs

- Educational, social, demographic, and geographic background

- Approach to innovation and innovative practices within the business

- Mind set and risks involved with innovation and ideas

- Enablers/ conditions to successful idea creation and execution

- Inhibiting factors pertaining to business success and ideas

- Instances of business success and failure.

(Ahlm \& Jeppsson, 2012)

The time frame of the study was cross-sectional. The participants within the sample were subjected to interviews at a specific point in time and not over a period. The phenomenon observed within the study was captured at the time the sample subjects were interviewed with their current state of knowledge of the business/industry and level of competency. The reason for this is to limit the variable factors that could contribute to the research question thereby increasing the likelihood of developing a heuristic to establish how to cultivate success in technology enabled business ventures (Martin, 2010).

The initial semi structured interview process provided a platform to extract large amounts of information regarding education and work experience, the entrepreneurial journey, idea generation and execution, iterative cycles of development, personality profiles, and other miscellaneous data. Thereafter, external data (via articles and testimonials) was gathered to corroborate the information provided in the interviews. The combination of the interview and external data showed a holistic view of the participating entrepreneurs.

Interview transcription was all done manually and listening to interviews again reinforced the facts being conveyed. Thereafter the data had to be coded into themes using qualitative analysis software called Nvivo. The themes were developed from the literature and by looking at the data and ascertaining potent recurring concepts within the interview data. The coding process required the researcher to re-read the transcribed interview and categorize the data into existing themes as well as creating new themes as they occurred in the coding process.

After the data was categorized into various themes, Nvivo allows the researcher to explore recurrent themes as well as linkages between themes. Using queries, such as word frequency searches, and other parameterized queries, the influential success factors became apparent. Displaying the query results in various forms, such as graphically or in tabular form, also aided the understanding of the data. The Nvivo coding process assisted in examining the unstructured data and linking patterns. Within this process, data sources were assimilated and gathered in reference to specific patterns and themes to create nodes.

The final phase of analysis revolved around manually analyzing data encompassed within each theme. For instance, the concept of partnerships was a recurrent theme in the data; therefore each entrepreneur's link to the concept of partnership was examined and cross referenced to note similarities and differences. The findings were recorded in conjunction with relevant literature that either contradicted or opposed the findings. The discussion aspect formed the final component of the rigorous analysis process, in which the findings were interpreted and related back to the research sub questions in order to answer the main research question, "What are the critical success factors that cultivate technology-enabled start-ups to be successful in South Africa?" 
The sample population included South African entrepreneurs that have created and executed ideas resulting in the establishment of successful business related to the technology sphere. These entrepreneurs have started these businesses within the last 15 years and employ innovation in some form. The sample included judgmental and snowball sampling methods. The reason for this is because of the approach taken and the narrow focus of the study.

The representation within the sample population took into account a very specific type of South African entrepreneur in terms of time, sector / industry and educational background relating to mind-set. The sample was not to be representative of the entire activity within the South African private sector; this can be done in further studies. The total sample set included approximately 20 interview participants which were used as instances in the case study.

There may be certain biases that exist within the sample population. All of the participants have a degree from the University of Cape Town. The degree is either a Bachelor of Commerce or Bachelor of Business Science. The biases may also be racial or demographic due to the accessibility of education and funding in South Africa. Further biases, in the data, may include a certain trained way of thinking and a narrow focus of the case study specific to certain industries.

Since a case study explores a research topic or phenomena within a number of real life contexts, this subjectivity in this regard can be accepted (Saunders et al., 2009).

\section{Analysis and Themes}

The ranking of the major themes as shown in Table 1, was done by aggregating the importance that each participant assigned to the various themes in which the most influential factors were identified in this study.

\begin{tabular}{|c|c|c|c|c|c|c|c|c|c|c|}
\hline & 氖 & 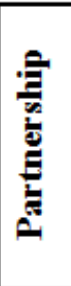 & 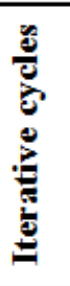 & 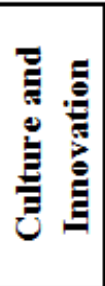 & 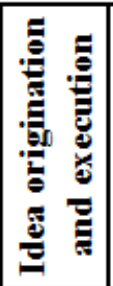 & 递 & 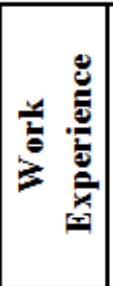 & 恶 & 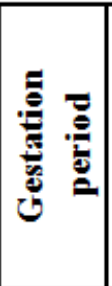 & $\stackrel{0}{a}$ \\
\hline P1 & $\mathrm{x}$ & $\mathrm{x}$ & $\mathrm{m}$ & $\mathrm{x}$ & $\mathrm{x}$ & $\mathrm{x}$ & $\mathrm{m}$ & $\mathrm{x}$ & $\mathrm{x}$ & Strong Influence (x) \\
\hline P2 & $\mathrm{x}$ & $\mathrm{x}$ & $\mathrm{x}$ & $\mathrm{x}$ & $\mathrm{x}$ & $\mathrm{m}$ & $\mathrm{m}$ & $\mathrm{m}$ & o & Point allocation $=1$ \\
\hline P3 & $\mathrm{x}$ & $\mathrm{x}$ & $\mathrm{x}$ & $\mathrm{x}$ & $\mathrm{x}$ & $\mathrm{m}$ & $\mathrm{m}$ & o & $\mathrm{m}$ & \\
\hline P4 & $\mathrm{x}$ & $\mathrm{m}$ & $\mathrm{x}$ & o & $\mathrm{m}$ & $\mathrm{x}$ & o & o & $\mathrm{m}$ & Medium Influence (m) \\
\hline P5 & o & $\mathrm{x}$ & $\mathrm{x}$ & $\mathrm{x}$ & $\mathrm{x}$ & o & $\mathrm{x}$ & o & $\mathrm{m}$ & Point allocation $=0.5$ \\
\hline P6 & $\mathrm{m}$ & o & o & o & o & $\mathrm{m}$ & $\mathrm{x}$ & o & o & \\
\hline P7 & $\mathrm{m}$ & $\mathrm{x}$ & $\mathrm{x}$ & $\mathrm{x}$ & $\mathrm{m}$ & $\mathrm{m}$ & o & o & o & Weak Influence (o) \\
\hline P8 & $\mathrm{x}$ & $\mathrm{x}$ & $\mathrm{m}$ & $\mathrm{x}$ & $\mathrm{m}$ & $\mathrm{m}$ & $\mathrm{x}$ & $\mathrm{x}$ & o & Point allocation $=0$ \\
\hline Totals & 6 & 6 & 6 & 6 & 5.5 & 4.5 & 3.5 & 2.5 & 2.5 & \\
\hline
\end{tabular}

Education and partnership were themes that received significant focus in the data. Another important theme was that of iterative cycles as ideas are executed, evolved, and linked with new ideas. Johnson (2011) uses the metaphor of having a "hunch" as the origin of what can become a 
good idea. This often happens in and is influenced by peer or social environments where ideas have the opportunity to 'connect', hatch, and become the basis for innovation, for example, the creation of the world-wide-web by Tim Berners-Lee. The theme of work experience resonated with the significance of organization and industry experience as noted by Gabrielsson and Politis (2012). Martin (2009) and Brown (2008) contend that design thinking and innovation are fundamental concepts, supporting the theme for innovation and culture that emerged from the data. The themes of intuition, personality, and risk were highlighted in a similar study where Ahlm and Jeppson (2012) explored the inhibitors of breakthrough, innovation, and entrepreneurship.

\section{Education}

Education was a common theme for most of the participants, except for participant 5 who did not dwell on it much. They commented on the inherent value of the systems development team project, a main deliverable in both the third and fourth year of the IS degree, for linking theory and practice. These projects honed skills related to client interaction, nurtured a deep understanding of systems and systems thinking, and provided real world business exposure. "I knew I could build a great system ... I had got my hands dirty" (Participant 1). Participant 1 also felt that those courses where lecturers shared their business experiences helped in sensitizing him to "what it means to deal with people in a systems and technology context". Participant 2 alluded to the fact that IS gave him a good technical knowledge that helped to link business and technology. The Finance and Accounting courses, for example, helped to build confidence in knowing how to value a business, whereas Professional Communication supported the vital skills of writing proposals and emails (Participant 1). For participant 3, it was all Finance, and for participant 4 Business Strategy was one of the biggest courses as well as the systems development projects in third and fourth year. Participant 6 mentioned that while many courses were worthwhile, not that many fostered entrepreneurial activity in a direct way, but neither did they detract from fostering entrepreneurship. Participant 8 claims that the value obtained from his honors (fourth) year was tangible in the sense that it gave him the ability to conceptualize. For participant 7 education instilled an appreciation for life-long learning, and he continues to challenge his employees to constantly learn something new in relevant areas that they are passionate about and sharing what they have learnt on regular occasions.

\section{Partnership}

Almost all of the participants reflected on the significance of engaging in some kind of partnership in different phases of their business start-up activities “... so in 2008, when we started running these online courses, people were skeptical. They said this is not the way to do education ... so we really had to sell the idea hard. The relationships we built at UCT were really important" (Participant 1). In the case of participant 2, the entrepreneurial business started with two partners and participant 2 joining in later, forming a group of diverse partners ... "initially three guys with ideas and putting them into action ...you could only really achieve that kind of collaboration and pace of development when you've got people who are really good at different things". Participant 3 said his profile indicated that he cannot make a decision in isolation - "I helped him with making his product bankable and he in turn would build my product". In the end, they discarded participant 3's product and focused only on the partner's product and eventually a third partner brought the funding.

For participants 7 and 8 partnerships grew out of the fourth year team projects. In the case of participant 7, this partnership continued directly after they graduated, whereas participant 8 's elearning company was initiated years later, as an extension to the successful business venture of one of his university team members. Partnerships and collaboration also proved to be important for participant 5 who shared a passion for marathons with her partner: "Honestly Victoria and I 
would spend days prototyping and trying to figure out how to express it on paper, so that was the biggest obstacle. Once we got to a point where we were happy with the prototype ... we could show people, things just seemed to flow".

Participants provided various reasons to indicate the significance of partnerships when cultivating a start-up business as depicted in Figure 2. This was also emphasized as a critical success factor throughout the literature and the primary data.

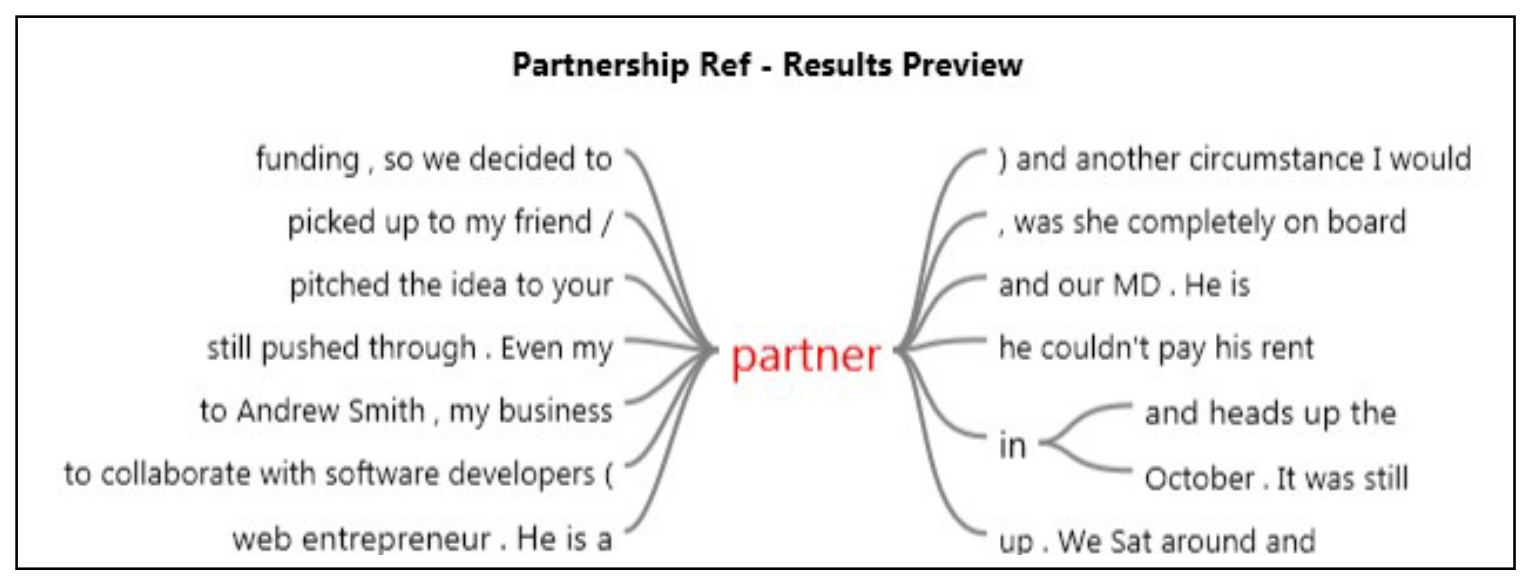

Figure 2: Nvivu partnership links

\section{Iterative Cycles}

The comment from participant 1 that an entrepreneurial start-up is like "navigating" an unchartered business landscape and experiencing the freedom it affords to "fail regularly and succeed often" (Participant 1) is representative of the common theme amongst all participants that iterative cycles are needed when starting a company and growing it towards sustainability. Simon (1996) argues that the use of multiple lenses is critical to make sense of and gain an understanding of the chaotic world created by the interaction between technology people and business. Participants supported this notion and, in almost all instances of a successful entrepreneurial start-up, entrepreneurs examined their ideas, businesses, and products in multidimensional ways to gain a deeper insight and to find alternative strategies or opportunities to improve and best serve customers. In the case of participant 2, all three partners carried on with their other jobs while following an iterative process of getting the new business off the ground. They started with a website that tried to sell only one product and this was expanded to include the one partner's passion for food and selling brand name products related to that, starting with a small shelf of 12 products only. Participant 3 sold some of his shareholdings in his company to start another in Zimbabwe and is convinced that when you have "a client who is willing to use and pay for a product, that is when you have a successful business". Participant 5 had a particular strong focus on iterative cycles as a result of her work experience and industry knowledge. When asked about her past or notable mistakes, participant 5 responded that she does not call them 'mistakes', rather previous versions. Going through previous versions provide insights valuable to complete a product - "It is hard for me not to think like a designer".

Participant 8 believes that one needs to "fail often, but fail fast". In his opinion, it is impossible to test for failure on a 'drawing board', one should rather subscribe to an emergent strategy of taking things off the drawing board and making small mistakes that will allow you to adjust quickly and move on. Participant 7 concurs by saying "frequency is more important than correctness", it is the speed of decision making that counts. 


\section{Idea Origination and Execution}

For many participants, the entrepreneurial journey started with idea generation and execution early in their lives. Johnson (2011) maintains that an idea is a thought executed according to a strategy. For participant 5, "it was actually solving a need. I am a runner so the idea stems from just wanting to improve my own life. That was the business opportunity! - "this isn't the first idea I've had; it's the one that has effortlessly come to life. It took a long time to express the idea ... I prototype ideas all day so I trusted my own formula for getting to the end product ...prototyping is intuitive to me". She also commented that "once you have an idea there is a journey to the end".

Participant 2 says that he has been "doing funny little projects for decades", one of which is a "sherbet empire" at the age of 6 . Participant 3 started a micro lending business when still at school and "made a lot of money". Participant 1 remembered that "when I was in standard 3, I started selling stickers around the playground ... a 19 year old ... got three contracts to design websites ... got a 1000 pounds and I could go travelling". Amongst these ventures, many failures were experienced. Participant 1 believes that if you are too far removed from a particular product, cutting it off quickly "is quite a critical success factor to managing and executing your ideas". In contrast, "if you know a lot about the idea and you have the capabilities within yourself and your team, you have a higher chance of succeeding". Participant 3 is convinced that if someone "steals your idea", you probably haven't done it right. "An idea is more than something you have in your head, it is implementation and execution" (Participant 3). Participant 4 maintained that his idea originated from frustration that was grounded in "the distrust and the miscommunication between software developers and clients", something he experienced "again and again". Participant 8 claims that as "success builds on success" there was merit in his opportunity; it was a credible idea as it linked to the successful venture of a trusting partner. It thus became the elaboration of a strategy and a relationship.

\section{The Intricacies of Innovation}

The participants of this study had varying understandings of innovation; they employed innovation in different ways and interesting relationships emerged from the data when they reflected on their respective journeys of innovation. These different perceptions of innovation are summarized in Figure 3. Participant 1 holds the view that innovation is a culture, and a major feature of this culture is that "it is okay to make mistakes"; if one tries to put constraints on innovation, it will be inhibited. Another feature is energy, as energy stimulates creativity which ultimately leads to innovation. "We have a fluff week of making micro improvements to systems in the business regardless of the use in the business" and "we also regularly introduce new ideas ... and just new things in general that give a general atmosphere of innovation so that people are open to and inspired to come up with recommendations". Participant 8 nurtures innovation by introducing excitement in the office though a quarterly theme such as "geek out".

Participant 7 agrees to driving innovation in his company by keeping a consistent flow of pressure alive with a philosophy that all should move through stages of purpose, mastery, and autonomy. This translates to having a purpose not only in one's personal lives, but also driven by a purpose of what you are strong at, mastering that to become self-organizing "autonomous" units.

For participant 3, the success of a business is about the team and getting people involved in the idea, it is about soft skills and it is also a client or a customer ... "Yes. Innovation is about serving your client ... clients buy two things, they buy a solution and they buy a good feeling". Participant 4 argues that innovation is being passionate and comes from a "collaborative mind-set ... talking to my mentor ... a source of knowledge ... and see other companies who are more mature ... how they do business ... I can measure the maturity of my company". Participant 5 perceived 
innovation as "when you have complete insight into something and you can act and have understanding of the space. That is innovation. Without that, it is superfluous design."

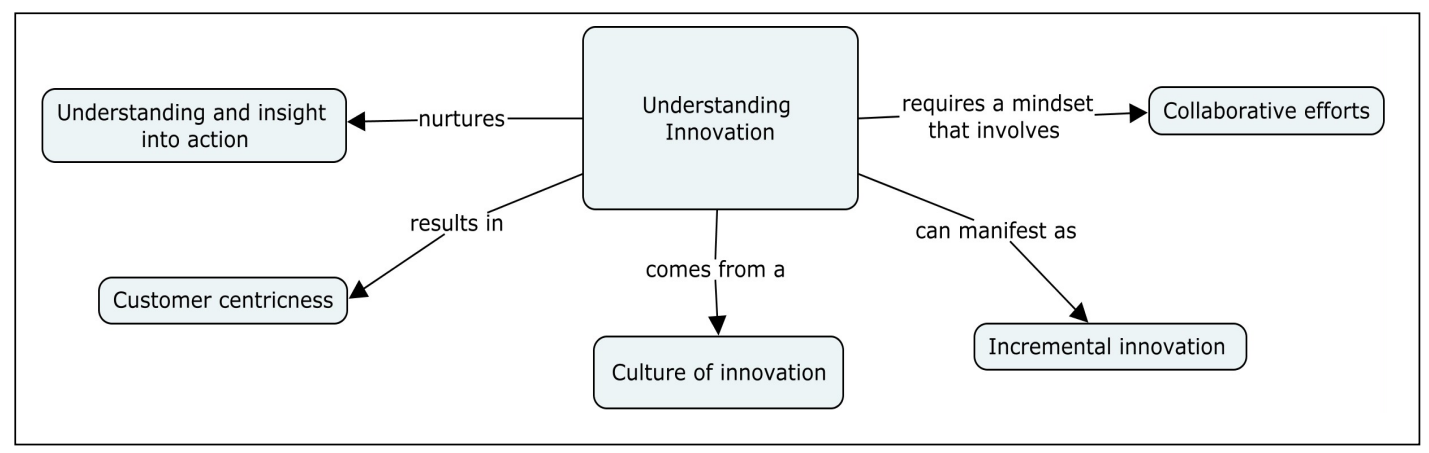

Figure 3: Understanding the concept of innovation

\section{Work Experience}

Work experience can result in the exposure and exploration of different avenues, actions and operations. Gabrielsson and Politis (2012) argue that variety is more important than work experience with great depth in one operation or field as the latter can have a negative impact idea generation in entrepreneurial start-ups. Participant 8 claims that the variety of his work experience was an absolute necessity. For example, as a software developer he learnt problem solving skills, and the valuable skills he learnt as a human resources manager gave him confidence. Participant 6 expressed the same sentiments and found that the seven or eight years of work experience prior to starting his own venture was essential to his field of specialization. For a number of the participants, work experience started with the third and fourth year "real-world" team projects. The team had already built confidence while spending most of the time working on these projects at the project sponsor's workplace. Participant 5 was a digital producer at a digital agency and learnt that taking the specifications to the developers too soon, before flaws in the design have been identified, would cause 'technical debt' and break the process. A better approach, she believed, would be to iron out the issues before taking them to the developers... for this "prototyping was organic and I enforced it”.

\section{Peer Environments}

The large class environment provided ample opportunities for diverse influences, whereas working with a small team of five people in a project environment provided intense peer group experience and client focus (Participant 1). The fact that being part of a group of peers to share entrepreneurial experiences works very well was echoed by participant 4 , who felt that his systems development team at university as well as the network he started building was important in terms of confidence and skills level basis. In the case of both participants 7 and 8 , team members from the university projects became business partners in their entrepreneurial ventures. Both participants 2 and 7 felt that, in the entrepreneurial environment of one's own company, you can create the space you want, a culture that will support everyone to find what they are best at and enjoy the most, "while still achieving our goals for the company". For participant 5, it was easy to talk about her ideas and show them to friends and like-minded people; she felt that actually gave "life to the project".

\section{Gut Feel/ Intuition}

Participant 1 feels that although he needs to be driven by gut feel when he gets started and a new venture may initially be intuition-based, as it grows, a shift needs to be made to think differently, 
to gather more "complete information," and to "be guided by my intuition and not led by it". Participant 5 is convinced that she trusts her gut with the caveat that she needs to understand the bigger picture when doing so. She will use her intuition only when there is enough data. Participant 8 agrees that one should follow your gut feel, since we as human being already make decisions emotionally long before the cognitive "kicks in". For participant 7 intuition plays a massive role when little information is available and decisions need to be made quickly, since "you don't know what you do not know". It is that "healthy paranoia - not the correctness" - that keeps one moving forward, recovering quickly from wrong decisions.

Participant 3 honestly believes, although he does not understand it, that instead of intuition or gut feeling "it was more conviction and a feeling that God was supporting me that kept me going through the process".

\section{Gestation Period}

"We will only take projects that are close to what we know and we will only give ourselves a few months in that project, and if we don't make money/revenue or have clients then we will stop" (Participant 1).

\section{Risk Taking}

When Participant 1 talks about the entrepreneurial journey, he contemplates that he likes taking risks. The same holds for participants 2, 5, and 7. Participant 7, though, emphasizes that it is valuable if there can be more than one partner, where one is more risk loving to drive the vision. It is often the more risk loving person that will allow a company to grow exponentially, beyond it boundaries. Participant 3 feels risk averse when it involves other people, but loves risk taking when it includes only himself, whereas participant 4, although risk averse, will take calculated risks. Participant 6 likes risks despite being very analytical. Participant 1 has to admit, though, that in order to become a better businessman, it is necessary to gather enough information to make informed decisions and therefore reduce "your risk in knowing". Maturana and Varela (1987) refer to "all doing is knowing and all knowing is doing" to illustrate that action and experience are inseparable.

\section{Discussion of Findings}

From the phenomena that emerged through the analysis of the data and the in depth literature review, it became apparent that establishing an entrepreneurial venture requires a journey to take place. This journey is in line with the transcendence through the knowledge funnel and will typically start with a precursor of an idea. Moving through 'mystery' phases where the idea is born and a gestation period is experienced to a more heuristic environment where the idea is developed, executed, and results in the development of the service or product. In a more controlled, 'algorithmic' environment the business can mature, be sustained, and grow until renewal becomes necessary to sustain the business and some of these processes start all over again.

With the emphasis of guiding students to become innovative practitioners and entrepreneurs it is inevitable that the landscape for teaching has changed over the past decade. Where academic institutions previously taught professionals to provide correct answers to issues in practice (Schön, 1983), they now have to mentor future professionals to unpack problems and grapple with complexities (Leavy, 2011). From the data, it became evident that education has an effect on entrepreneurship and an indirect correlation exists between education and the fostering of entrepreneurship. Sometimes the impact becomes evident in the later stages of business growth, maturity, and capacity to sustain. "I think a system development course is the reason IS honours graduates are doing well and starting their own businesses because you are given the real world exposure. 
There aren't really other programmes in commerce that do that. So that is the thing that really contributed to me being an entrepreneur. I look at friends around me, going into their own business from IS and they will probably say the same." - Participant 1. Education thus imparts a way of thinking and learning; it is a precursor to entrepreneurship and valuable long-term partnerships form as a result of education.

From the analysis, it was evident (see Figure 2) that the value of partnerships manifested in every facet of the entrepreneurial journey. Partnerships were necessary for idea generation and execution. In addition, partnerships provided a pool of resources where different partners can leverage their most significant talents, skills, or aptitudes, thus allowing for specialization and diversity within a team. Participant 3 reflected on the concept of partnerships as follows: "My belief in business is that you need 3 critical people for the success of a business. First, you need the entrepreneur. The person that is flying around and inspiring and coming up with ideas and products. Then you need a manager, a person who gives the solution. And finally you need a developer". Partnerships formed before or during the commencement of iterative cycles aided the start-up company in gaining traction and collaborating collectively towards a common goal of success.

Although it is clear from the findings that a number of iterative cycles might contribute to entrepreneurial success, the optimum number of cycles or the different types of iterations may vary depending on the particular situation or the type of business. Winter and Szczepanek (2009) support this by saying that, while all projects depend on action and things like timescales, etc., all action depends on the image of what needs to be done. This image-action relationship has serious implications for a successful implementation. Leavy (2011, p. 21) argues that a design thinking approach can strengthen this relationship by implementing different strategies, like integrative thinking to address issues and tensions more effectively, thus evolving better solutions to problems as well as yielding a higher level of customer satisfaction and aid entrepreneurial success within a start-up environment. Brown $(2008$, p. 86) defines design thinking as a "methodology that imbues the full spectrum of innovation activities with a human-centered design ethos". The data analysis confirmed that a customer-centric approach, especially when combined with iterative cycles for continuous improvement and evaluation, yields greater entrepreneurial success. For example, participant 8 holds that the "client-drive" for innovation although an abstract entity is vital for your business venture's reputation and you must live up to that. For participant 7 all in the company should be driven by the same purpose, that of "helping the commuters", their clients, contributing passionately to a larger social world with the belief that some commodities should be "as free as the air we breathe".

The literature and the data highlighted that the generation of ideas provides an impetus for different iterations cycles. Ideas (or hunches) become more useful by amassing implicit knowledge over time which leads to the development and maturity of an idea until a tipping point is reached. It therefore seemed necessary to give some consideration to how ideas originate. Leavy (2011) argues that "wicked" business problems or dilemmas usually do not fit the current mode of thinking, often contradict existing models for solving these issues, and may even cause frustration. Participant 4 echoed this sentiment by saying that his idea was born out of frustration, both some of his own frustration as well as the frustration felt when experiencing "the distrust and the miscommunication between software developers and clients".

In addition to this, the passion for the idea and a passion for entrepreneurial success are also key drivers for idea generation. "On the one hand, it started off as a passion for just succeeding. I wanted to succeed and I wanted the world to see me as successful and I wanted to see myself as successful so you put in a lot of effort and you try hard to try and make it work" (Participant 1).

The data analysis revealed little evidence of what stage in the entrepreneurial journey innovation was the most influential. According to Martin (2010) innovation is critical to the success of new 
business ventures as well as in their capacity to sustain growth and financial success. What emerged from the data was that the significance of innovation depended on the entrepreneurs' definition of innovation as well as on the culture and hierarchy of the organization and the industry in which the new business operates. Participant 5 - "I think there is a misconception about creativity. It takes brain storming and brain stirring and reports and revisions to be in this industry". De Bono (1995, p. 14) concurs and argues that "creativity is not a natural process in the brain", we need to force ourselves to think laterally and logically - "thinking laterally cuts across patterns".

Another common feature that emerged from the data was that innovation and ideas need systems in place to allow for growth. Brown (2008) supports this notion by arguing that innovation without some degree of structure could yield "superfluous" results. This is illustrated by participant 7's implementation of the theory of purpose, mastery, and autonomy. Weekly meetings are structured and implemented to guide and mentor employees to transcend through these stages while collaborating and sharing information about their tasks and roles in the company.

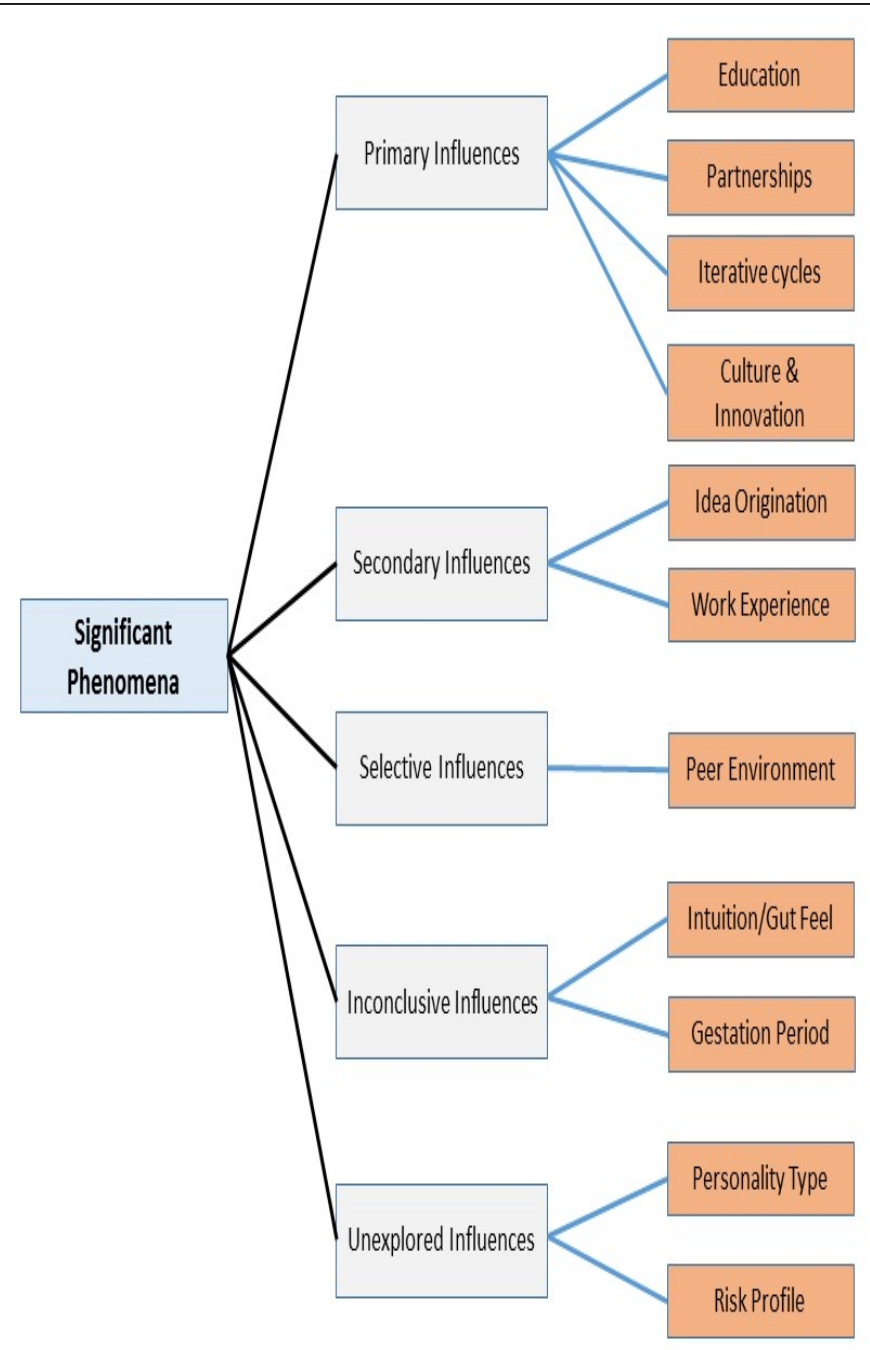

Figure 4: Linkages between major phenomena (themes) 
Figure 4 provides a summary of the primary success influencers such as different types of education, the formation of partnership, iterative cycles, and the use of innovation and organizational culture. The secondary influencers were seen as the origination of an idea and work experience. When analyzing the interviews, it was often difficult to get a clear distinction between peer environments and the role of partnerships, as many of the partnerships originated from previous shared experiences in healthy and resourceful peer environments. This was therefore marked as selective influences in Figure 4. Themes such as the use of intuition and gestation period for ideas proved elusive in nature and could not be conclusive correlated to success or failure and thus marked as inconclusive in Figure 4.

By exploring emergent themes, entrepreneurs can have a clearer roadmap to success within a South African context, which impacts both the economic and innovation progress of a developing country like South Africa.

\section{Conclusion}

Despite the fact that creativity and entrepreneurship have been identified as necessary stimuli for economic growth (Matthews, 2007), the Gordon Institute of Business Science (GIBS) (2009), as mentioned earlier, reported that the entrepreneurial activity dropped significantly from $10.4 \%$ in 2013 to an all-time low of $6.79 \%$ in 2014 . This statistic creates a concern for the future of entrepreneurial ventures in South Africa. Currently little research is done into the inhibitors and contributors of phenomena that may influence the success of technology-enabled ventures. As a result, this preliminary study to identify phenomena that play a significant role when entrepreneurs implement creative ideas, specifically in the context of a developing country, provides an important foundation for further research.

A significant outcome of this study was the important role that partnerships play in the success of entrepreneurial start-ups. Seven out of the eight participants experienced their first taste of innovation and creativity through the group systems development project of their capstone and/or fourth year course. All of these participants confirmed that the real world experience of the team projects laid the foundation for them to venture into entrepreneurial start-ups explored in this study. From this study it transpired that success vastly improves with more than one partner. Different perspectives and the fact that risk can be shouldered between the risk-loving partner and the one that is more risk adverse contribute to sustainability, growth as well as stability. Another influence of a partnership lies in the credibility of the idea that is founded in a trust relationship with a partner, which could have existed and/or developed over time, affording merit for the opportunity.

A factor that differentiates this paper from other research in the area is the fact that all the participants are alumni of the Department of Information Systems and the Commerce Faculty of the same university. Although this may be perceived as a limitation as it accounts for some biases and a narrow focus, it provides a solid foundation for further research.

There were a number of themes that require further research to fully establish their impact on entrepreneurial success and those include the use of intuition, the gestation period of ideas, personality and risk profiles, and peer environments. Future researchers should work to unravel the mystery surrounding entrepreneurial intuition/ gut feel and have methods to qualify and measure such concepts.

\section{Acknowledgements}

This manuscript was based on and extended an empirical research project, titled: What are the critical success factors that cultivate entrepreneurial technology-enabled start-ups to be successful in South Africa?" by Terrina Govender in 2013. We want to thank the anonymous reviewers of 
the InSITE 2016 conference, the editor in chief of the Informing Science Journal and professor Grandon Gill for their suggestions and valuable comments.

\section{References}

Ahlm, P., \& Jeppsson, J. (2012). Exploring inhibitors for implementation of ideas with breakthrough innovation potential - A case study of SCA Hygiene business area. (Master of Science, Management and Economics of Innovation Masters), Chalmers University of Technology, Göteborg, Sweden.

Attride-Stirling, J. (2001). Thematic networks: An analytic tool for qualitative research. Qualitative Research, 1(3), 385-405.

Audretsch, D., \& Belitski, M. (2015). Creativity filter and start-ups to resolve the innovation paradox. In K. Lui, K. Nakata, W. Li, \& D. Galarreta (Eds.), Information and Knowledge Management in Complex Systems: 16th WG 8.1 International Conference on Informatics and Semiotics in Organisations (ICISO 2015) (Vol. 449, pp. 195-203): IFIP International Federation for Information Processing.

Brown, T. (2008). Design thinking. Harvard Business Review, 86(6), 84.

Brown, T., \& Katz, B. (2011). Change by design. Journal of Product Innovation Management, 28, $381-$ 383.

Brown, T., \& Wyatt, J. (2010). Design thinking for social innovation IDEO. Retrieved from https://openknowledge.worldbank.com/bitstream/handle/10986/6068/deor_12_1_29.pdf?sequence=1

Campos, H. M., Parellada, F. S., Quintero, M. R., Alfonso, F., \& Valenzuela, A. (2015). Creative thinking style and the discovery of entrepreneurial opportunities in startups. Revista de Negócios: Studies on emerging countries, 20(1), 3-12. doi:10.7867/1980-4431.2015v20n1p3-12

Carayannis, E. G., Samara, E. T., \& Bakouros, Y. L. (2014). Innovation and entrepreneurship. Theory, policy and practice. Springer International.

Cohen, E. (1999). Reconceptualizing information systems as a field of the transdiscipline, informing science: From ugly duckling to swan. Journal of Computing and Information Technology (CIT), 7(3), 213-219.

Cohen, E. (2009). A philosophy of informing science. Informing Science, the International Journal of an Emerging Transdiscipline, 12, 1-15.

Cohendet, P., \& Simon, L. (2015). Introduction to the special issue on creativity in innovation. Technology Innovation Management Review, 5(7), 5-13.

Cooke, B., \& Zaby, A. (2015). Skill gaps in business education: fulfilling the needs of tech startups in Berlin. Journal of Higher Education Theory and Practice, 15(4), 97-112.

De Bono, E. (1995). Serious creativity. The Journal for Quality and Participation, 18(5), 12-18.

Dodgson, M., Gann, D., \& Coopmans, C. (2008). Playful technologies: Creativity, innovation and organization. Paper presented at the Entrepreneurship and Innovation - Organizations, Institutions, Systems and Regions (25th celebration), June 17 - 20, 2008, Copenhagen, CBS, Denmark.

Einstein, A. (n.d.). The most beautiful thing we can experience is the mysterious. It is the source of all true art and science. Living Philosophies. http://www.goodreads.com/quotes/282814-the-most-beautifulthing-we-can-experience-is-the-mysterious.

Gabrielsson, J., \& Politis, D. (2012). Work experience and the generation of new business ideas among entrepreneurs. International Journal of Entrepreneurial Behavior \& Research, 18(1), 48-74. doi:http://dx.doi.org/10.1108/13552551211201376

GIBS. (2009). The entrepreneurial dialogues state of entrepreneurship in South Africa. Retrieved from http://led.co.za/sites/default/files/FINAL_GEW WhitePaper_18March.pdf

Gill, G. (2011). When what is useful is not necessarily true: The underappreciated conceptual scheme. Informing Science: the International Journal of an Emerging Transdiscipline, 14, 1-32. 
Gill, G. (2015a). Informing science, volume one: Concepts and systems. Santa Rosa, California: Informing Science Press.

Gill, G. (2015b). Informing science, volume two: Design and research issues. Santa Rosa, California: Informing Science Press.

Gill, G., \& Murphy, W. (2011). Task complexity and design science. Paper presented at the 9th Conference on Education and Information Systems, Technologies and Applications (EISTA), Orlando, Florida.

Guilford, J. P. (1950). Creativity. American Psychologist, 5(9), 444-454.

Hevner, A. R., March, S. T., \& Park, J. (2004). Design science in information systems research. MIS Quarterly, 28(1), 75-105.

Hill, R. C., \& Levenhagen, M. (1995). Metaphors and mental models: Sensemaking and sensegiving in innovative and entrepreneurial activities. Journal of Management, 21(6), 1057-1074.

Hirschheim, R., \& Klein, H. K. (2012). A glorious and not-so-short history of the information systems field. Journal of the Association for Information Systems (JAIS), 13(4), 188-235.

Holmes, O.W. (1809 - 1894). Man's mind, once stretched by a new idea, never regains its original dimensions. http://www.quotationspage.com/quote/26186.html

Johnson, S. (2011). Where good ideas come from: The seven patterns of innovation. London, United Kingdom: Penguin.

Jordi, R. (2011). Reframing the concept of reflection: Consciousness, experiential learning, and reflective learning practices. Adult Education Quarterly, 61(2), 181-197. doi:10.1177/0741713610380439

Leavy, B. (2011). Roger Martin explores three big ideas: Customer capitalism, interactive thinking and design thinking. Strategy \& Leadership, 39(4), 19-26.

Leshem, S., \& Trafford, V. (2007). Overlooking the conceptual framework. Innovations in Education and Teaching International, 44(1), 93-105. doi:10.1080/14703290601081407

Martin, R. (2009). The design of business. Boston, Massachusetts, USA: Harvard Business Press.

Martin, R. (2010). Design thinking: Achieving insights via the "knowledge funnel". Strategy \& Leadership, 38(2), 37-41. doi:10.1108/10878571011029046

Matthews, J. H. (2007). Creativity and entrepreneurship: Potential partners or distant cousins? Paper presented at the Managing Our Intellectual and Social Capital: 21st ANZAM 2007 Conference, 4-7 December 2007, Sydney, Australia.

Maturana, H. R., \& Varela, F. J. (1987). The tree of knowledge: The biological roots of human understanding (R. Paolucci, Trans.). Boston, MA, USA: Shambhala Publications, Inc.

Merleau-Ponty, M. (1962). Phenomenology of perception. London, UK: Routledge and Kegan Paul.

Mezirow, J. (1990). How critical reflection triggers transformative learning. In J. Mezirow and Associates (Eds.), Fostering critical reflection in adulthood: A guide to transformative and emancipatory learning, pp. 1-6. San Francisco, CA: Jossey-Bass.

Mezirow, J. (1997). Transformative learning: Theory to practice. New Directions for Adult and Continuing Education, 74, 5-12.

Naggar, R. (2015). The creativity canvas: A business model for knowledge and idea management. Technology Innovation Management Review, 5(7), 50-58.

Okpara, F. O. (2007). The value of creativity and innovation in entrepreneurship. Journal of Asia Entrepreneurship and Sustainability, 3(2).

Peppard, J., \& Ward, J. (2004). Beyond strategic information systems: Towards IS capability. Journal of Strategic Information Systems, 13, 167-194. doi:10.1016/j.jsis.2004.02.002 
Saunders, M., Lewis, P., \&Thornhill, A. (2009). Research methods for business students (5th Ed). London, United Kingdom: Pearson Education.

Schön, D. (1983). The reflective practitioner: How professionals think in action. New York, NY, USA: Basic Books.

Simon, H. A. (1996). The sciences of the artificial (3rd ed.). London, UK: The MIT Press.

Singer, S., Amoros, J. E., \& Arreola, D. M. (2014). Global entrepreneurship monitor (GEM). Retrieved from http://www.babson.edu/Academics/centers/blank-center/globalresearch/gem/Documents/GEM\%202014\%20Global\%20Report.pdf

Schmitt, U. (2015). Putting personal knowledge management under the macroscope of informing science. Informing Science: the International Journal of an Emerging Transdiscipline, 18, 145-176. Retrieved from http://www.inform.nu/Articles/Vol18/ISJv18p145-175Schmitt1634.pdf

Walsham, G. (2006). Doing interpretive research. European Journal of Information Systems (EJIS), 15, 320-330.

Walsham, G. (2012). Are we making a better world with ICTs? Reflections on a future agenda for the IS field. Journal of Information Technology (JIT), 27(2), 87-93. doi:10.1057/jit.2012.4

Winter, M., \& Szczepanek, T. (2009). Images of projects. Surrey, UK: Gower Publishing Limited.

Yanow, D., \& Tsoukas, H. (2009). What is reflection-in-action? A phenomenological account. Journal of Management Studies, 46(8), 1339- 1364. doi:10.1111/j.1467-6486.2009.00859.x

Zhao, F. (2005). Exploring the synergy between entrepreneurship and innovation. International Journal of Entrepreneurial Behaviour \& Research, 11(1), 25-41. doi:10.1108/13552550510580825

\section{Biographies}

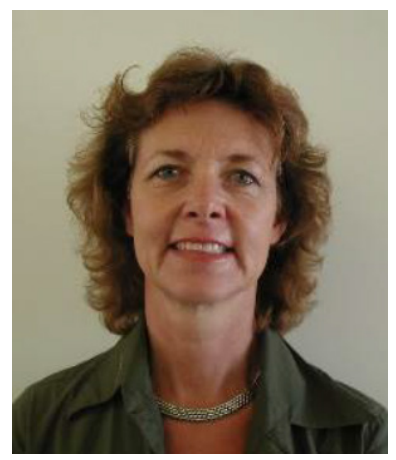

Elsje Scott is an associate professor at the Department of Information Systems, University of Cape Town and has 30 years' experience in teaching programming and systems development project related courses at tertiary institutions. The author's main research interest is the practice of capstone courses, comprising the integrated and interactive environments of project management, systems development, technology and people. This research-led pedagogy resulted in the development of a theory of coherent practice for capstone courses as published in the author's PhD study, in 2012.

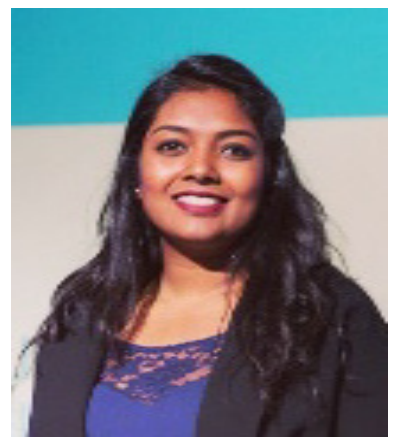

Terrina Govender is a consultant in the field of international development (with specific emphasis on ICT for Development) as well as a social entrepreneur focused on using technology to improve social outcomes in Sub-Saharan Africa. Terrina has also worked for Google and remains a fellow of the United Nations Agency, ITU. Her main research interest is the behavioural implications and phenomenology around tech entrepreneurship in frontier economies 


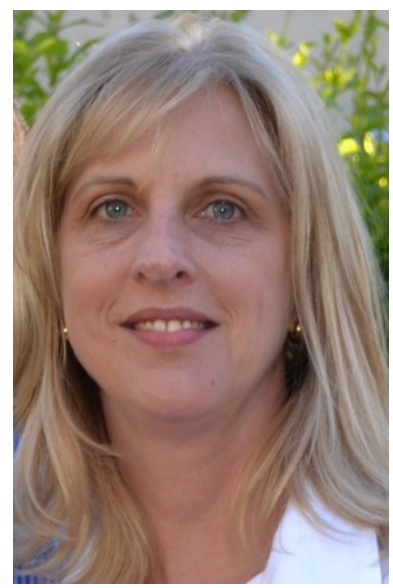

Nata van der Merwe has 28 years experience - 10 years as an IS/IT professional and 18 years as an IS/IT lecturer, lecturing at the University of Cape Town (UCT) as well as the Cape Peninsula University of Technology (CPUT). Her main research interest is the use of projectbased teaching as a teaching-and-learning strategy. 